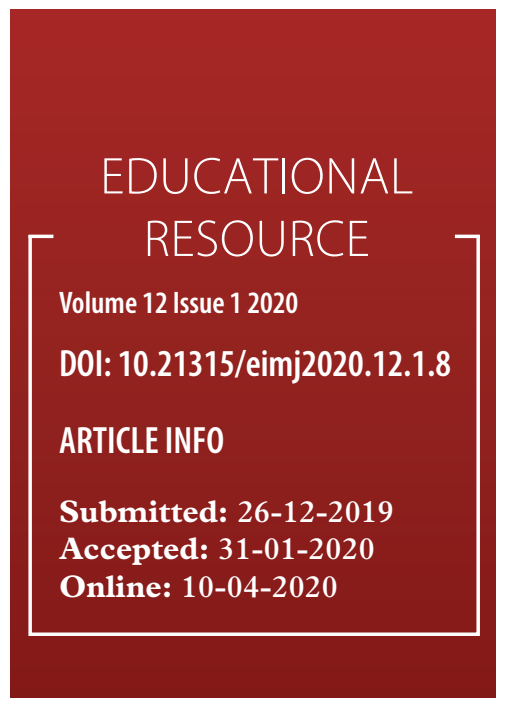

\title{
Seven Steps to Construct an Assessment Blueprint: A Practical Guide
}

\author{
Muhd Al-Aarifin Ismail, Mohamad Najib Mat Pa, Jamilah Al- \\ Muhammady Mohammad, Muhamad Saiful Bahri Yusoff \\ Department of Medical Education, School of Medical Sciences, \\ Universiti Sains Malaysia, Kelantan, MALAYSIA
}

To cite this article: Ismail MA-A, Mat Pa MN, Mohammad JAM, Yusoff MSB. Seven steps to construct an assessment blueprint: a practical guide. Education in Medicine Journal. 2020;12(1): 7180. https://doi.org/10.21315/eimj2020.12.1.8

To link to this article: https://doi.org/10.21315/eimj2020.12.1.8

\begin{abstract}
Blueprint is a map or specification of assessment items based on educational outcomes and its primary function is to support the validity of assessment with regard to its content - content validity. It helps to align assessment items with the intended learning outcomes and students learning experience. The primary focus of this study is to describe seven practical steps in the construction of an assessment blueprint. The steps are somehow flexible, as we try to elaborate the possibilities. This study covers several issues that might arise during blueprinting construction and suggestions on how to tackle the issues. A well-constructed blueprint is essential and important to ensure the validity of any assessment content is aligned with the intended learning outcomes and learning experience.
\end{abstract}

Keywords: Blueprinting, Assessment blueprint, Student assessment, Validity, Constructive alignment

CORRESPONDING AUTHOR

Muhd Al-Aarifin Ismail, Department of Medical Education, School of Medical Sciences, Universiti Sains Malaysia, 16150 Kubang Kerian, Kelantan, Malaysia | Email: alaarifin@ usm.my

\section{INTRODUCTION}

Blueprint is defined as a complete plan that explains how to do or develop something (1). In assessment, the term refers to a map or specification of assessment to ensure that all aspects of the curriculum and educational domains are covered by the assessment programmes over a specified period of time (2). It helps curriculum developers to match various competencies with the course content and the appropriate modality of assessment (3). Assessment blueprint is an essential step for enhancing validity of assessment and constructive alignment particularly for high stakes examinations (4).

\section{Validity of Assessment}

Blueprinting acts as a valid tool to align objectives with assessment, helps in distribution of appropriate weightage and questions across the topics. It should be an integral part of assessment (5) and the process of blueprinting will act as a source of evidence to support its content validity (6). As far as threat of validity is concerned, educators must seriously consider any element that can reduce the validity of assessments. As described by Messick (7), there are two major sources of validity threats which are construct under representation and construct-irrelevant variance (8). Construct under representation 
refers to the under sampling or biased sampling of the curriculum or course content for assessment. It occurs when there are too few items covering a curricular content. Construct-irrelevant variance on the other hand occurs because of flawed item formats, items that are too easy or too hard, or the choice of inappropriate test modalities. In general, the aim of the blueprinting is to reduce these two major threats to validity. It helps institutions to identify test instruments appropriate to the constructs and contents of the assessment. Although its primary function is to validate evaluation content, a wellconstructed blueprint can also serve other functions such as guiding the selection of learning experiences (9).

\section{Constructive Alignment}

The three pillars of education consist of intended learning outcomes, teaching and learning activities, and assessment tasks (Figure 1) - it is referred as the constructive alignment (10). The congruence between these three pillars of education can be facilitated by a blueprint $(11,12)$. It will ensure the assessment tasks are aligned with the intended learning outcomes and teaching and learning activities.
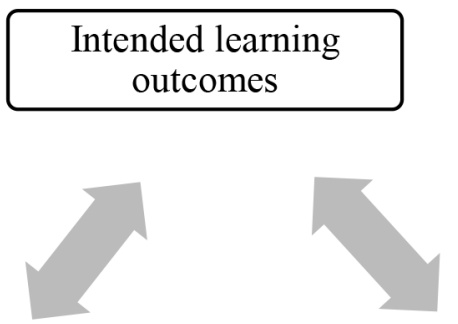

Teaching and
learning
activities

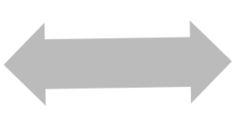

\section{Assessment} tasks

Figure 1: Constructive alignment.

\section{BENEFITS OF ASSESSMENT BLUEPRINT}

Blueprint helps to match various competencies with the course content and the appropriate modality of assessment (3). Recent study by Patil et al. (5) found that blueprinting helps to:

a. Ensure questions being asked in examination are aligned to objectives.

b. Ensure that there are no questions that are out of syllabus.

c. Make assessment fair to the students.

d. Design the instructional strategies.

e. Ensure that the selected test items provide appropriate emphasis on thinking skills and assessment of in-depth knowledge.

f. Sample content, competencies and tools for the assessment in a rational and balanced manner.

\section{BLUEPRINTING PROCESS AT SCHOOL OF MEDICAL SCIENCES, UNIVERSITI SAINS MALAYSIA (USM)}

The school adopts SPICES curriculum (13) that has two phases - Phase I (pre-clinical) consists of Year 1 and Year 2, and Phase II (clinical) consists of Year 3 until Year 5. This study described seven practical steps for creating a blueprint based on School of Medical Sciences practice. Department of 
Medical Education facilitates the blueprinting process through series of workshops and prior to the workshops, a template of blueprint is prepared, and it consists of a series of rows and columns using Microsoft Excel software (Table 1). The flow of the blueprinting workshops is described in Figure 2.

\section{Blueprinting Construction}

\section{Step 1: Define the blueprinting purpose and scope}

The first step in any blueprinting construction is to identify its purpose and scope. The following questions should be addressed during this initial step:

a. Which semester or phase of study the blueprint is prepared for?

b. How many academic session the blueprint is prepared for?

c. Which courses are involved?

d. What is the assessment tools involved?

e. How many questions for each assessment tool?

These are some of the crucial questions that should be answered during the first stage of blueprinting construction. In our example, the blueprint for this course is prepared for GMT 104 (Microbiology, Immunology and Pathology course). It is prepared for Semester 1, Professional I and Supplementary examinations. It is prepared for 2017/2018 academic session. The assessment tools involved are multiple true false (MTF), short essay question (SEQ) and objective structured clinical examination (OSCE). The total numbers of questions needed are 14 for MTF, four questions for SEQ and three questions for OSCE. For Professional I and Supplementary Professional I Examination, six questions of MTF and one SEQ question for each set. No OSCE question is required for this course (Table 1).

The other important question that needs to be addressed is about the institution standard statements for the students in that phase to be achieved. The standard statement is: "The graduate of this medical programme should demonstrate adequate knowledge for safe clinical decision and management, be able to work with supervision, equipped with standard clinical skills, and conduct themselves professionally".

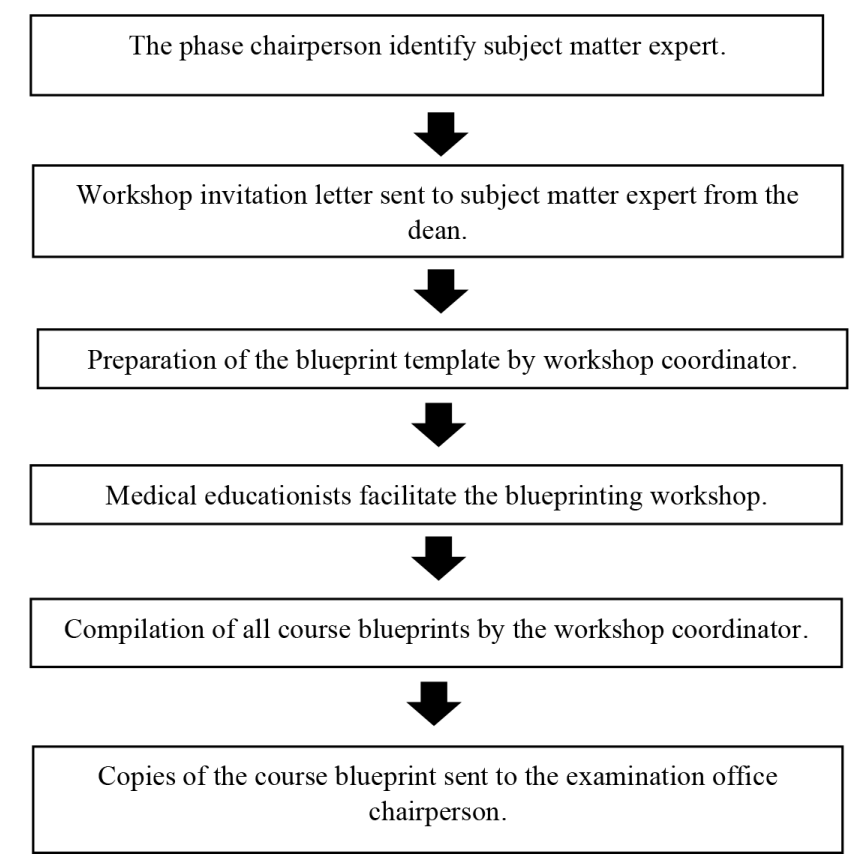

Figure 2: The flow of the blueprinting workshop at School of Medical Sciences, USM. 


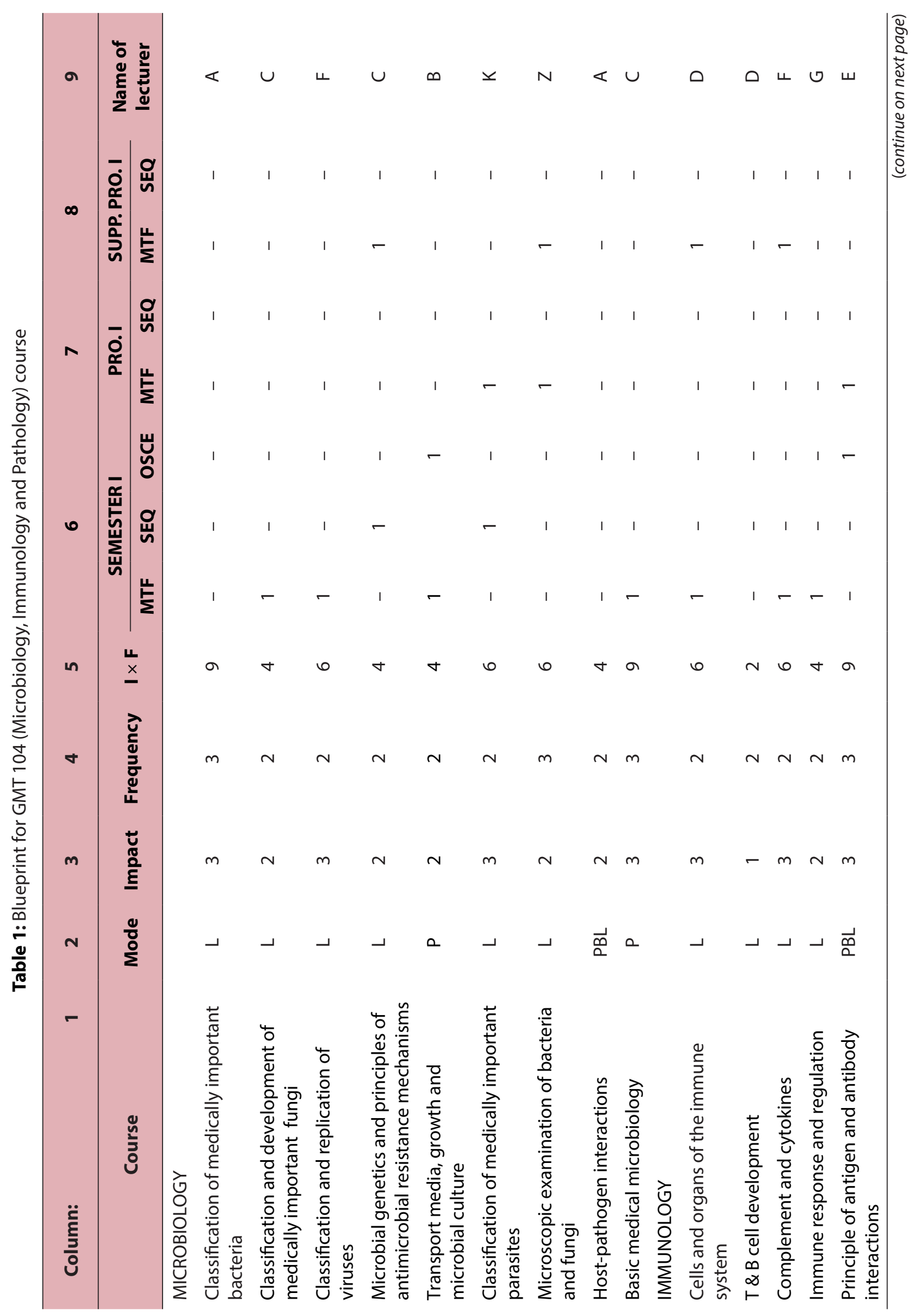


EDUCATIONAL RESOURCE | Practical Guide to Construct an Assessment Blueprint

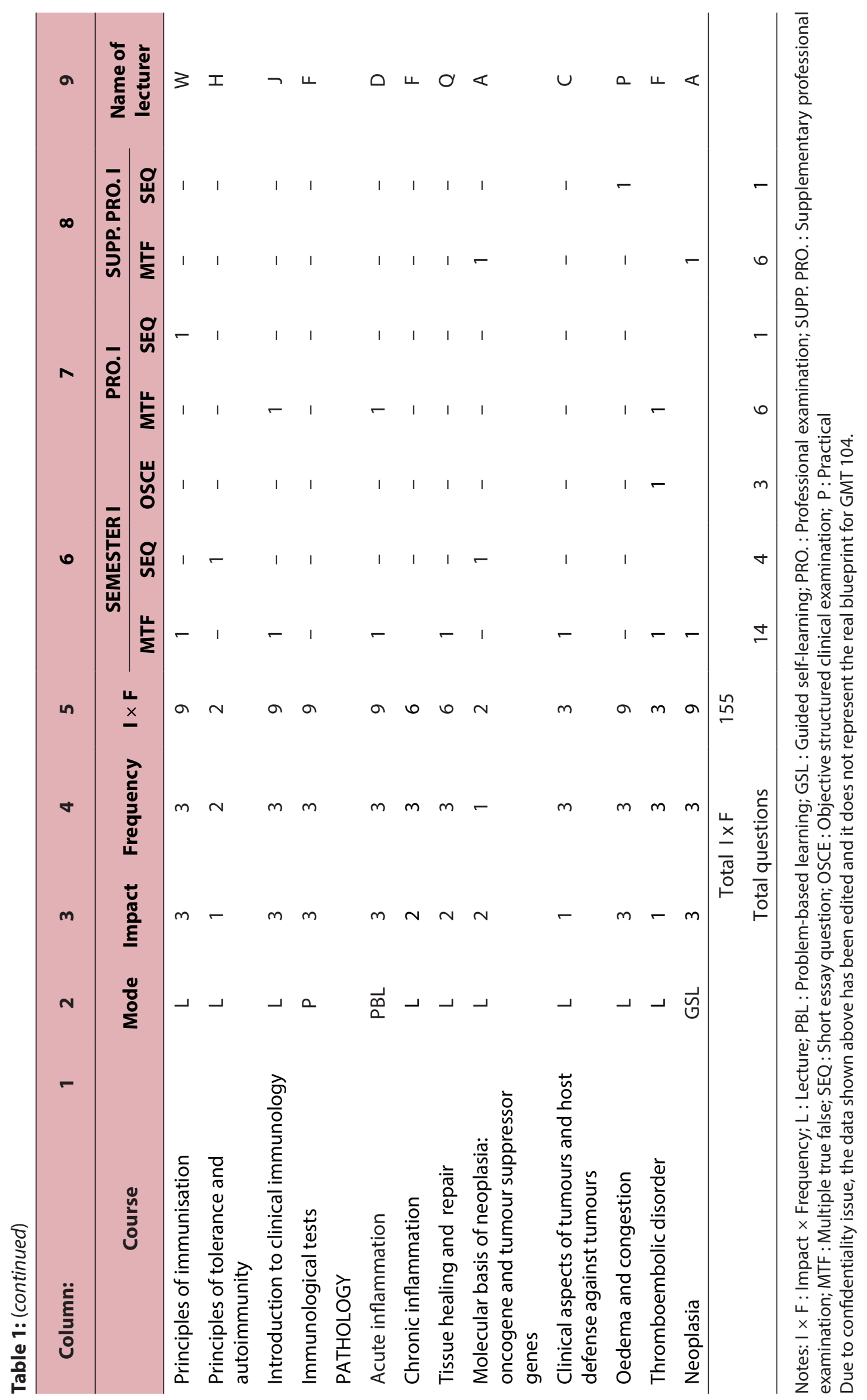




\section{Step 2: Tabulate curricular content (Column 1)}

The curricular content can be listed in many ways according to curricular setting. It can be listed according to course learning outcomes, clinical presentations, topics (lectures, practical session) and many more. At School of Medical Sciences, teaching of the undergraduate curriculum is organised according to course topics, therefore the curricular content listed in our blueprints contain the list of topics. Column 1 in Table 1 shows the 26 topics for this course.

\section{Step 3: Identify impact and frequency (Column 3 and 4)}

Each assessment has a predetermined number of items. The number of items cannot be simply distributed equally based on the list of curricular content. This is because each curricular content has different level of importance. Some measure of relative weighting of content areas must be decided beforehand so that priority can be given to major areas when creating items
(14). However, the content importance level is not easy to define (14).

At School of Medical Sciences, the impact and frequency of each curricular content are based on the criteria shown in Table 2 and Table 3. For Phase 1, the criteria for impact and frequency are different with Phase 2 due to different training level. For Phase 1, the focus is more on preparing the students for Phase 2, whereas the focus of Phase 2 is to produce novice competent house officers. The weightage for each curricular content is produced by multiplying the impact and frequency $(\mathrm{I} \times \mathrm{F})$. This produces $\mathrm{I} \times \mathrm{F}$ product (Column 5) for curricular content which ranges from 1 to 9 .

University of Calgary blueprinting process has their own approach to define impact and frequency (14). Potential life-threatening conditions or the potential for significant disease prevention and how frequently a presentation is encountered in clinical practice is considered (see Table 4).

Table 2: Weighting criteria for impact and frequency of the curricular contents for undergraduate Phase 1 at the School of Medical Sciences

\begin{tabular}{llll}
\hline & \multicolumn{1}{c}{ Impact } & & \multicolumn{1}{c}{ Frequency } \\
\hline 1 & Less important for Phase 2 & 1 & Rarely applied in Phase 2 \\
2 & Important for Phase 2 & 2 & Commonly applied in Phase 2 \\
3 & Very important for Phase 2 & 3 & Frequently applied in Phase 2 \\
\hline
\end{tabular}

Table 3: Weighting criteria for impact and frequency of the curricular contents for undergraduate Phase 2 at the School of Medical Sciences

\begin{tabular}{llll}
\hline & \multicolumn{2}{c}{ Impact } & \multicolumn{1}{c}{ Frequency } \\
\hline 1 & Less important for house officers & 1 & Rarely applied in clinical practices \\
2 & Important for house officers & 2 & Commonly applied in clinical practices \\
3 & Very important for house officers & 3 & Frequently applied in clinical practices \\
\hline
\end{tabular}


Table 4: Weighting criteria for impact and frequency of the clinical presentations for undergraduate renal course at the University of Calgary

\begin{tabular}{llll} 
& & \multicolumn{1}{c}{ Impact } & \multicolumn{1}{c}{ Frequency } \\
\hline 1 & Non-urgent, little prevention potential & 1 & Rarely seen \\
2 & Serious, but not immediately life threatening & 2 & Relatively common \\
3 & Life threatening emergency and/or high potential for & 3 & Very common \\
& prevention impact & & \\
\hline
\end{tabular}

\section{Step 4: Categorise curricular content based on relative weightage}

At School of Medical Sciences, the curricular contents are classified into "must know", "should know" and "nice to know" (3) based on their I $\times$ F. For any curricular content that has $I \times F$ of 6 or 9 , they are classified under "must know" knowledge, for curricular content that has $\mathrm{I} \times \mathrm{F}$ of 3 or 4, they are considered as "should know" knowledge, whereas for curricular content that has $\mathrm{I} \times \mathrm{F}$ of 1 or 2 , they are put under "nice to know" knowledge. All curricular contents will then be arranged and put into their categories in different sheet in the Microsoft Excel file.

Alternative technique in determining weightage is by dividing the $\mathrm{I} \times \mathrm{F}$ for each curricular content (column 5 of Table 1) with the total for the $\mathrm{I} \times \mathrm{F}$ column (155 in our example) to provide a relative weighting for each curricular content, which corresponds to the proportion of evaluation items for this presentation. The higher the number produced, the more important the curricular content, thus more questions should be constructed from these curricular contents.
It is worth to note that, the first technique is more suitable for any assessment that has less questions number compared to the number of curricular content items, whereas the second technique is more suitable for any assessment that has more number of curricular content items as compared to total number of questions.

\section{Step 5: Decide on percentage of questions for each category}

As discussed earlier, the questions cannot be distributed equally throughout the curricular content. Logically, more questions should be asked from "must know" category and less questions from "should now" and "nice to know". The percentage of questions for each category may vary from one blueprint to the others. Therefore, we need to decide on percentage of each category in every blueprinting process. How many percent questions from "must know", "should know" and "nice to know" knowledge? At School of Medical Sciences, particularly for Phase 1 curriculum, we have decided to take $60 \%$ for "must know", $30 \%$ for "should know" and $10 \%$ for "nice to know" content.

Table 5: Classification of curricular content based on their weightage

\begin{tabular}{llcccccccc}
\hline \multirow{2}{*}{ I $\mathbf{~}$ F } & \multirow{2}{*}{ Category } & \multirow{2}{*}{ Percentage } & \multicolumn{3}{c}{ SEMESTER I } & \multicolumn{2}{c}{ PRO. I } & \multicolumn{2}{c}{ SUPP. PRO. I } \\
\cline { 4 - 10 } & & & MTF & SEQ & OSCE & MTF & SEQ & MTF & SEQ \\
\hline $6-9$ & Must know & $60 \%$ & 13 & 3 & 2 & 6 & 1 & 6 & 1 \\
$3-4$ & Should know & $30 \%$ & 6 & 2 & 1 & 1 & 0 & 1 & 0 \\
$1-2$ & Nice to know & $10 \%$ & 1 & 0 & 0 & 0 & 0 & 0 & 0 \\
\hline Total & & $100 \%$ & 20 & 5 & 3 & 7 & 1 & 7 & 1 \\
\hline
\end{tabular}


For the second technique, to get the number of questions for each curricular, multiply the total number of items on the evaluation with the relative weighting for each curricular content, and then round it up or down to the nearest whole number.

\section{Step 6: Decide on number of item for each assessment task (Column 6, 7, 8)}

As discussed earlier, each assessment task should have its predetermined number of items. Based on the information from Step 5, we can now decide on how many questions should be constructed from each category. For example, the number of items cannot be equally distributed based on the list of curricular content.

There are variety of tasks that can be evaluated for any curricular content. Each curriculum has their own assessment task, be it for theory or clinical assessments and have been decided earlier. These tasks must be consistent with the learning outcomes and teaching activities for that course. For example, to assess theories or cognitive skills, we can use multiple choice questions and OSCE to assess clinical skills.

\section{Step 7: Assign questions to lecturers for items preparation (Column 9)}

The final step in blueprint construction is to identify question makers for items preparation. Practically, the one who teaches the topic should prepare the questions. However, there are circumstances whereby other lecturers need to prepare the questions. It can be discussed during this stage (Table 6).

Table 6: The summary of seven steps in constructing a blueprint

\begin{tabular}{lll}
\hline \multicolumn{1}{c}{ Steps } & \\
\hline $\begin{array}{l}\text { 1. Define the blueprinting } \\
\text { purpose and scope }\end{array}$ & $\begin{array}{l}\text { Identify its purpose and scope. } \\
\text { For which semester or phase of study? } \\
\text { Which academic session? } \\
\text { Which courses? } \\
\text { What assessment tools? }\end{array}$ \\
& How many questions? \\
2. Tabulate curricular content & $\begin{array}{l}\text { Curricular contents - course learning outcomes, clinical presentations } \\
\text { or topics - are listed based on curricular setting. }\end{array}$ \\
3. Identify impact and & The impact and frequency for each curricular content are identified \\
frequency & based on the selected criteria. \\
4. Categorise curricular content & The curricular contents are classified as "must know", "should know" \\
based on relative weightage & and "nice to know" knowledge. \\
5. Decide on percentage of & Determine how many percent questions should be constructed from \\
"questions for each category & "must know", "should know" and "nice to know" knowledge. \\
6. Decide on number of item & Decide on how many questions should be constructed for each \\
for each assessment task & category of curricular content. \\
7. Assign questions to lecturers & Identify question makers for items preparation. Practically, the one \\
for items preparation & who teaches the curricular content should prepare the questions. \\
\hline
\end{tabular}




\section{ISSUES RELATED TO BLUEPRINT}

USM Department of Medical Education has been conducting many workshops on blueprint construction. We have come across many issues related to the blueprinting process. There are a couple of commonly asked questions that should be addressed in this study. First, if we use the weighting criteria for impact as mentioned in Table 4, what would happen to curricular content which are very important i.e., life threatening (impact, $I=3$ ) but not frequent (frequency, $F=1$ ). These types of curricular content would fall under "nice to know" category. Thus, possibility of these curricular content to be selected will be lesser compared to other curricular content. For this issue, we suggest that any life-threatening condition will automatically be classified under "must know" category irrespective of their frequency. Therefore, these types of cases will have higher chance to be selected.

Second issue is about disclosure of the blueprint to students. Can it be distributed to the students? Some institutions do distribute their blueprint to students and some do not. It was reported that distributing assessment blueprint to students do not improve student performance, but significantly increased the perception of fairness of the evaluation process (15). Our suggestion for this issue is that, it depends on the institutional policies. Different institution will have their own policies. If we disclose the blueprint to students, will it lead to strategic learning? In other word, if we distribute the blueprint to students, will they only study on the curricular content which will come out in examination? Theoretically yes, but based on study, the theory is unsupported (14). Our suggestion is simple, if the total number of curricular content is more than the number of questions; we suggest not disclosing it to students since disclosure of these blueprints might lead to strategic learning. However, if the number of curricular content is less than the number of questions, then it is not a problem to distribute the blueprint to students since they will study all the curricular content listed.

\section{CONCLUSION}

This study described seven practical steps to construct a blueprint. Based on the experience handling blueprinting process, solutions to several issues related to weightage of curricular content and dissemination of the blueprint to students were discussed. Despite it is a resource intensive process, it will provide the utmost benefit to both teachers and learners. This is because a well-constructed blueprint is a valuable educational tool that can improve the quality of assessment in medical education, and thus will ensure the highest quality of graduates produced.

\section{ACKNOWLEDGEMENTS}

This collaborative work was funded by the USM Short Term Grant (304/ PPSP/61313161). We would like to thank USM for allowing us to conduct the series of blueprinting workshop at its institutions and our greatest appreciation to our dean and deputy dean (academic \& alumni) who are very supportive. Special thanks also to our entire USM School of Medical Sciences faculty members.

\section{REFERENCES}

1. Cambridge University Press. Blueprint. In: Cambrigde Dictionary. 2018. Available at: https://dictionary.cambridge.org/dictionary/ english/blueprint

2. Sood R, Paul V, Mittal S, Adkoli B, Sahni $P$, Kharbanda O. Assessment in medical education: trends and tools. New Delhi: KL Wig CMET, AIIMS; 1995. 
3. Adkoli B, Deepak K. Blueprinting in assessment: principles of assessment in medical education, 1st ed. New Delhi, India: Jaypee Brothers Medical Publishers Ltd; 2012. p. 205-13. https://doi.org/10.5005/jp/ books/11647_19

4. Boland J, Finn Y, Geoghegan R. Blueprinting assessment to enhance constructive alignment. 2014. In: 16th Ottawa Conference, Transforming Healthcare through Excellence in Assessment and Evaluation. 25-29 April. Ontario, Canada.

5. Patil SY, Gosavi M, Bannur HB, Ratnakar A. Blueprinting in assessment: a tool to increase the validity of undergraduate written examinations in pathology. Int J Appl Basic Med Res. 2015;5(Suppl 1):S76-9. https://doi.org/10.4103/2229516X.162286

6. Sireci SG. The construct of content validity. Social Indicators Research. 1998;45(13):83-117. https://doi.org/10.1023/A:10069 85528729

7. Messick S. Validity. In: Linn R, editor. Educational measurement. New York: Macmillan Publishing; 1989. p. 13-103.

8. Downing SM, Yudkowsky R. Assessment in health professions education. UK: Routledge; 2009. https://doi.org/10.4324/ 9780203880135

9. Hamdy H. Blueprinting for the assessment of health care professionals. The Clinical Teacher. 2006;3(3):175-9. https://doi.org/10 $.1111 /$ j.1743-498X.2006.00101.x
10. Biggs J. Constructive alignment and why it is important to the learning process. UK: The Higher Education Academy; 1999.

11. Bordage G, Brailovsky C, Carretier H, Page G. Content validation of key features on a national examination of clinical decisionmaking skills. Acad Med. 1995;70(4):27681. https://doi.org/10.1097/00001888-199 504000-00010

12. Bridge PD, Musial J, Frank R, Roe T, Sawilowsky S. Measurement practices: methods for developing content-valid student examinations. Med Teach. 2003;25(4):414-21. https://doi.org/10.1080/ 0142159031000100337

13. Harden RM, Sowden S, Dunn WR. Educational strategies in curriculum development: the SPICES model. Med Educ. 1984;18(4):284-97. https://doi.org/10 $.1111 / \mathrm{j} .1365-2923.1984 . t b 01024 . x$

14. Coderre S, Woloschuk W, McLaughlin K. Twelve tips for blueprinting. Med Teach. 2009;31(4):322-4. https://doi.org/10.1080/ 01421590802225770

15. McLaughlin K, Lemaire J, Coderre S. Creating a reliable and valid blueprint for the internal medicine clerkship evaluation. Med Teach. 2005;27(6):544-7. https://doi .org/10.1080/01421590500136113 